\title{
Burden of Pertussis in Individuals with a Diagnosis of Asthma: A Retrospective Database Study in England
}

\author{
Amit Bhavsar (D) \\ Emmanuel Aris $\left(\mathbb{D}^{2}\right.$ \\ Lauriane Harrington (1D ${ }^{3}$ \\ Jason C Simeone $\mathbb{D}^{4}$ \\ Anna Ramond (iD) ${ }^{5}$ \\ Dimitra Lambrelli (iD ${ }^{5}$ \\ Alberto Papi $\mathbb{D D}^{6}$ \\ Louis-Philippe Boulet $\mathbb{D}^{7}$ \\ Kinga Meszaros $\mathbb{1 0}^{8}$ \\ Nicolas Jamet ${ }^{8}{ }^{8}$ \\ Yan Sergerie $\mathbb{D}^{3}$ \\ Piyali Mukherjee $\mathbb{D}^{3}$ \\ 'Europe Medical Affairs, GSK, Wavre, \\ Belgium; ${ }^{2}$ Real-World Analytics, GSK, \\ Wavre, Belgium; ${ }^{3}$ Global Medical Affairs, \\ GSK, Wavre, Belgium; ${ }^{4}$ Real-World \\ Evidence, Evidera Inc., Waltham, MA, \\ USA; ${ }^{5}$ Real-World Evidence, Evidera Ltd, \\ London, UK; ${ }^{6}$ Respiratory Medicine, \\ University of Ferrara, Ferrara, Italy; \\ ${ }^{7}$ Department of Medicine, Laval \\ University, Quebec City, Quebec, \\ Canada; ${ }^{8}$ Value Evidence and Outcomes, \\ GSK, Wavre, Belgium
}

Correspondence: Amit Bhavsar $\mathrm{Tel}+3210855111$

Email amit.b.bhavsar@gsk.com
Purpose: The impact of pertussis in individuals with asthma is not fully understood. We estimated the incidence, health care resource utilization (HCRU), and direct medical costs (DMC) of pertussis in patients with asthma.

Patients and Methods: In this retrospective cohort study, the incidence rate of pertussis (identified using diagnostic codes) among individuals aged $\geq 50$ years with an asthma diagnosis was assessed during 2009-2018 using Clinical Practice Research Datalink and Hospital Episode Statistics databases. HCRU and DMC were compared - between patients with diagnoses of asthma and pertussis (asthma+/pertussis + ) and propensity score-matched patients with a diagnosis of asthma without pertussis (asthma+/pertussis-) - in the months around the pertussis diagnosis $(-6$ to +11$)$.

Results: Among 687,105 individuals, 346 had a reported pertussis event (incidence rate: 9.6/ 100,000 person-years of follow-up; 95\% confidence interval: 8.6-10.7). HCRU and DMC were assessed among 314 asthma+/pertussis + patients and 1256 matched asthma+/pertussiscontrols. Baseline HCRU was similar in both cohorts, but increases were observed in the asthma + pertussis + cohort from -6 to -1 month before to $2-5$ months after diagnosis. Rates of accident and emergency visits, general practitioner (GP)/nurse visits, and GP prescriptions were 4.3-, 3.1-, and 1.3-fold, respectively, in the asthma+/pertussis+ vs asthma+/pertussiscohorts during the month before diagnosis; GP/nurse visit rates were 2.0- and 1.2-fold during 0-2 and 2-5 months after diagnosis, respectively (all $p<0.001$ ). DMC was 1.9- and 1.6-fold during the month before and 2 months from diagnosis, respectively, in the asthma+/pertussis + vs asthma+/pertussis- cohorts (both $p<0.001$ ). During months -1 to +11 , DMC in the asthma+/pertussis + cohort was $£ 370$ higher than in the asthma+/pertussis- controls.

Conclusion: A pertussis diagnosis among adults aged $\geq 50$ years with asthma resulted in significant increases in HCRU and DMC across several months around diagnosis, suggesting lengthy diagnosis times and highlighting the need for prevention strategies.

Keywords: asthma, direct medical costs, health care resource utilization, incidence, pertussis

\section{Plain Language Summary}

Why Was the Study Done?

- Pertussis (whooping cough) is a highly contagious respiratory bacterial infection. Individuals with asthma appear to be at higher risk of pertussis diagnosis than people without asthma.

- What happens when people with asthma get pertussis is unclear. 
What Did the Researchers Do and Find?

- Among individuals with a diagnosis of asthma who were aged $\geq 50$ years, there were approximately 10 pertussis cases diagnosed per 100,000 people per year (in England during 2009-2018), with a maximum of 21 per 100,000 in 2012.

- In the month before the pertussis diagnosis, patients with diagnoses of asthma and pertussis (asthma + /pertussis + ) had more general practitioner/nurse visits and accident and emergency visits and received more prescriptions (particularly for asthma medications and antibiotics) than patients with a diagnosis of asthma without pertussis (asthma + /pertussis-).

- During the 5 months from the pertussis diagnosis, asthma + /pertussis + patients continued to have more general practitioner/nurse visits than asthma+/pertussis- patients.

- This increase in health care use around a pertussis diagnosis resulted in significant increases in health care costs.

- The overall health care costs associated with an episode of pertussis among individuals aged $\geq 50$ years with a diagnosis of asthma were $£ 370$.

What do These Results Mean?

- These results highlight the need for increased awareness of pertussis infection among older adults with a diagnosis of asthma, and the need to consider preventive measures in this population.

\section{Introduction}

Pertussis (also known as whooping cough) is a highly contagious respiratory infection commonly caused by Bordetella pertussis. ${ }^{1}$ It is characterized by paroxysmal cough, posttussive vomiting, inspiratory whooping, and absence of fever in adults. ${ }^{2}$ It can also result in complications such as urinary incontinence, sinusitis, and pneumonia, especially among older adults. ${ }^{3}$ Pertussis is often perceived as a childhood illness, ${ }^{4}$ but only around one third of pertussis notifications in England in 2019 were in children aged 0-14 years, with another third in individuals aged 15-44 years, and the remaining third in adults aged $\geq 45$ years. ${ }^{5}$ The overall incidence of laboratory confirmed pertussis cases across all age groups in England in 2019 was 7 per 100,000 population $^{6}$ (approximately 5 notifications per 100,000 among those aged $\geq 45$ years), 5,7 but seroprevalence studies from Europe indicate that the true rate of pertussis infection could be hundreds or even thousands of times higher than the reported incidence. ${ }^{8-10}$ Data from patients with chronic obstructive pulmonary disease (COPD) in England also support this under-recognition, as the rate of diagnosed pertussis was approximately 5 per 100,000 in $2013,{ }^{11}$ but a seroprevalence study in the same year indicated that $5.8 \%$ of COPD patients had antibody levels indicative of exposure to $B$. pertussis in the past year. ${ }^{12}$ Pertussis is particularly under-recognized or misdiagnosed in adults, ${ }^{13,14}$ possibly because health care providers often view pertussis as a childhood disease, ${ }^{15}$ instead suspecting acute bronchitis or simply "cough", ${ }^{16}$ also because adults can be asymptomatic ${ }^{17}$ or present with mild or atypical symptoms. ${ }^{18}$

Asthma affects approximately $7 \%$ of adults in the United Kingdom (UK) based on data from 2016. ${ }^{19}$ Individuals with asthma appear to be at increased risk of pertussis $^{18,20,21}$ and hospitalization after a pertussis diagnosis. ${ }^{21}$ For example, in a United States (US) database study, the incidence of diagnosed pertussis was 27 vs 7 per 100,000 person-years (PY) among people aged $\geq 11$ years with asthma vs matched people without asthma or COPD. $^{21}$ In an Australian cohort study of adults aged $\geq 45$ years, pertussis incidences were approximately 160 vs 90 per 100,000 PY for those with vs without asthma. ${ }^{20}$ In a US study, hospitalized pertussis patients were approximately three times more likely to have asthma than the overall population. ${ }^{22}$ In a Canadian study, patients with asthma and pertussis had a longer period of paroxysmal coughing and more nights of disturbed sleep than people with pertussis without asthma. ${ }^{3}$ Most also had to increase their use of bronchodilators. ${ }^{3}$ Patients with asthma or COPD have also been reported to incur higher health care resource utilization (HCRU) and direct medical costs $(\mathrm{DMC})^{21}$ than those with pertussis alone. Among adults with COPD, a diagnosis of pertussis has been associated with higher HCRU and DMC, ${ }^{11}$ but the additional burden of asthma and pertussis compared to asthma alone has not yet been studied.

The objectives of the current study were to: (1) estimate the incidence rate of reported pertussis among individuals aged $\geq 50$ years with a history of asthma in England (during 2009-2018) and (2) compare HCRU and DMC among patients with diagnoses of asthma and pertussis (asthma+/pertussis + ) and those with a diagnosis of asthma without pertussis (asthma+/pertussis-).

\section{Materials and Methods Data Sources and Ethics}

Data from the primary care Clinical Practice Research Datalink (CPRD) GOLD and Aurum datasets were used, 
along with data from the following linked datasets: Hospital Episode Statistics (HES) Admitted Patient Care, HES Outpatient, HES Accident and Emergency (A\&E), and 2015 Index of Multiple Deprivation (IMD). Further details are provided in Supplementary Text 1.

The study protocol received CPRD ethics approval via the Independent Scientific Advisory Committee on March 4, 2020 (protocol number 20_043). The study complied with all applicable laws regarding subject privacy.

\section{Study Design}

This observational study (GSK study identifier HO-18-19690) used two different designs. Firstly, a retrospective cohort design was used to assess the reported incidence rate of pertussis among individuals aged $\geq 50$ years with a diagnosis of asthma. Secondly, a propensity score-matched cohort analysis was used to evaluate HCRU and DMC among two cohorts of patients: asthma+/pertussis + vs asthma + /pertussis- . HCRU and DMC were estimated during various timeframes (see Figure 1) on either side of the index date, which was the date of first pertussis diagnosis for the asthma + /pertussis + cohort. For the asthma+/pertussis- comparators, the index date was the date of pertussis diagnosis of the corresponding pertussis case as determined by propensity score matching.

\section{Patient Populations Incidence Rate}

For the estimation of pertussis incidence rate, we included patients aged $\geq 50$ years with a diagnosis of asthma ( $\geq 1$ of the diagnosis codes detailed in Supplementary Tables 1-3) who were registered with general practices in the CPRD GOLD and Aurum datasets during January 2009 through November 2018. Patients with a prior history of pertussis (see Supplementary Tables 4-8) were excluded, and the incident pertussis diagnosis (identified using the diagnosis codes listed in Supplementary Tables 6-8) had to be on or after the earliest asthma diagnosis. For GOLD practices, their up-to-standard date (showing continuous recording of patient data) had to be within the study period.

\section{Health Care Resource Utilization and Direct Medical Costs}

For the evaluation of HCRU and DMC, patients aged $\geq 50$ years with a diagnosis of asthma who had a pertussis diagnosis during January 2009 through August 2018 (to allow for 3 months of follow-up) were propensity score matched (1:4) to individuals aged $\geq 50$ years with a diagnosis of asthma who had no pertussis diagnosis during January 2009 through November 2018 or end of follow-up. Patients were required to have continuous CPRD enrolment for $\geq 18$ months before the index date.

\section{Baseline Characteristics}

Baseline characteristics, which are only reported for the matched cohorts for the HCRU/DMC analysis, include:

- At the index date: age, sex, ethnicity, year, season, and IMD (based on location of residence)

- Most recent record during the 18 months before the index date: body mass index and forced expiratory volume in 1 second percentage predicted

- During 18 months before index: obesity, asthma-related hospitalizations (defined as overnight hospitalizations with a primary diagnosis code of asthma, with admissions $<14$ days apart considered as the same event) and treatment corresponding to Global Initiative for Asthma (GINA) 2020 treatment step 4/5 (i.e., a prescription for

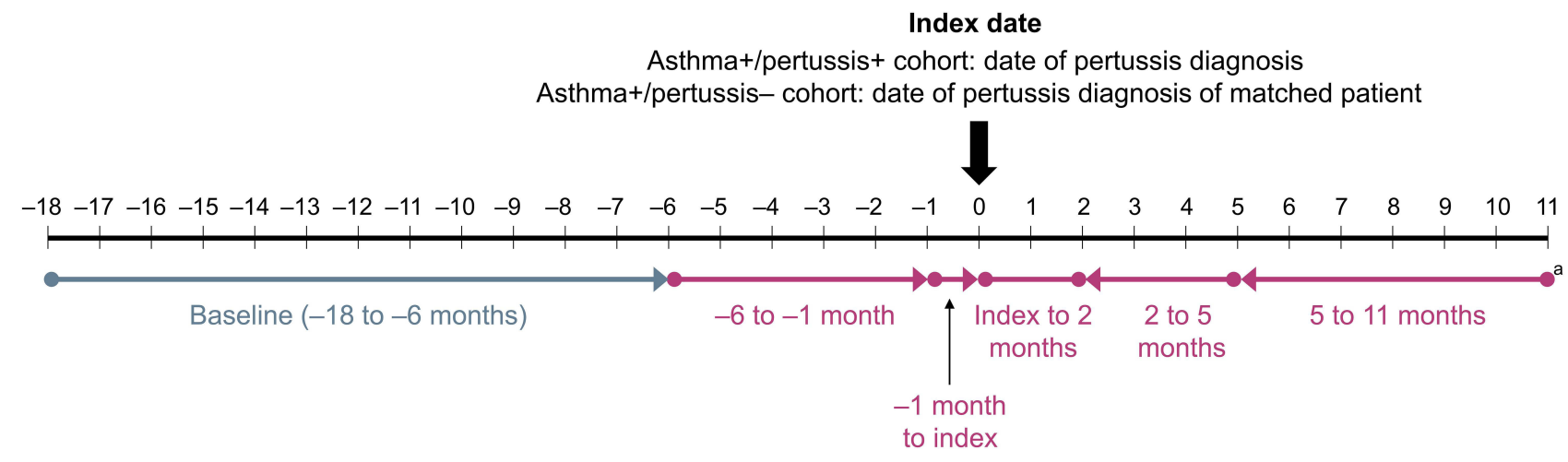

Figure I Study periods. ${ }^{a}$

Notes: ${ }^{a}$ Round arrow ends indicate that the time period starts or ends exactly on the indicated time point; pointed arrow ends indicate that the time period ends the day before (for right-facing arrows) or starts the day after (for left-facing arrows) the indicated time point.

Abbreviations: asthma+/pertussis+, patients with diagnoses of asthma and pertussis; asthma+/pertussis-, patients with a diagnosis of asthma without pertussis. 
a medium- or high-dose inhaled corticosteroid/longacting beta 2 agonist combination) ${ }^{23}$

- Most recent record from 18 to 6 months before index: smoking status

- From 18 to 6 months before index: HCRU and DMC

- During 10 years before index: pertussis vaccination (a 10-year duration was chosen based on the expected duration of immunity ${ }^{24}$ )

- Any time before index: COPD, chronic or persistent cough, heart failure, diabetes mellitus, hypertension, hyperlipidemia, malignant cancer, lung cancer, anxiety, depression, osteoporosis, orthopedic or musculoskeletal surgery, gastroesophageal reflux disease, stroke (identified by the relevant Read, Systematized Nomenclature of MEDicine, or International Classification of Diseases, 10th revision codes in primary or secondary care).

\section{Endpoints}

Incidence Rate

Incident pertussis was identified using diagnosis codes (Supplementary Tables 6-8). Pertussis incidence rates among patients with a diagnosis of asthma aged $\geq 50$ years were estimated for the whole 10-year study period (overall and for each 5-year age group) and per calendar year (all patients).

\section{Health Care Resource Utilization}

HCRU was estimated and compared between patients aged $\geq 50$ years in the asthma + /pertussis + vs asthma + /pertussiscohorts. HCRU included all-cause: general practitioner (GP)/nurse visits, GP prescriptions, outpatient specialist visits, A\&E visits, and hospitalizations. HCRU was measured monthly (per 30-day period) and during various time intervals (see Figure 1) from -6 months to +11 months around the index date.

\section{Direct Medical Costs}

Annualized DMC (reported in $2019 \mathfrak{f}$ ) - from the perspective of the National Health Service (NHS) - were estimated during the time intervals shown in Figure 1 based on the identified HCRU multiplied by the relevant unit costs.

Unit costs for GP, nurse, and outpatient specialist visits were derived from the 2019 Unit Costs of Health and Social Care published by the Personal Social Services Research Unit from the University of Kent. ${ }^{25}$ Unit costs for the five most commonly prescribed medications (in the asthma +/pertussis + cohort; during each time interval shown in Figure 1) were derived from the September 2019 NHS Drug Tariff. ${ }^{26}$ Unit costs for the five most common clinical assessments (e.g., blood pressure, weight, laboratory tests) and A\&E costs were derived from the 2018/2019 National Schedule of NHS Reference Costs. ${ }^{27}$

As hospitalizations are financed using Healthcare Resource Groups (HRGs) in the UK, 2018/2019 HRG4+ Reference Costs Grouper software ${ }^{28,29}$ was used to assign an HRG code for each hospitalization. ${ }^{30}$ Costs were then derived by matching the assigned HRG code and hospitalization type ${ }^{30}$ with those in the 2018/2019 National Schedule of NHS Reference Costs. ${ }^{27}$ Further costing details can be found in Supplementary Text 2 .

\section{Statistical Analysis}

All statistical programming was performed using SAS software version 9.4. Statistical methods pertaining to each part of the study are provided below.

\section{Incidence Rate}

Pertussis incidence rates (overall, by year, and by age group) were estimated by dividing the number of incident pertussis cases by the number of PY at risk. Individuals contributed to the person-time at risk from the latest of: study start date, start date of continuous registration, asthma diagnosis, the middle of the year in which they turned 50 (full birth dates were not available), or the date at which the practice had an "up-to-standard" flag (CPRD GOLD only). Ninety-five percent confidence intervals (95\% CIs) were calculated using the "exact" method by means of the Poisson distribution. ${ }^{31}$

\section{Propensity Score Matching}

Asthma + /pertussis + patients aged $\geq 50$ years were propensity score matched (1:4) to asthma + /pertussis- patients aged $\geq 50$ years. Baseline variables used to calculate the propensity score (based on the literature ${ }^{21,23,32-34}$ and expert consultation) were: age, sex, environmental/socioeconomic deprivation (IMD), smoking status, DMC, severe asthma (treatment corresponding to GINA 2020 treatment step 4/5), asthmarelated hospitalizations, and presence of hypertension, hyperlipidemia, depression, anxiety, and COPD. Further details can be found in Supplementary Text 3 .

\section{Baseline Characteristics}

Baseline characteristics after propensity score matching are described as means and standard deviations for continuous variables, and as numbers and percentages for 
categorical variables. Standardized mean differences (SMDs) were used to assess match quality and balance in baseline characteristics for continuous and binary variables, with SMDs $<0.20$ considered to indicate balanced values. For multilevel categorical variables where the SMD could not be estimated, $p$-values were used to estimate the balance between matched cohorts. Further details can be found in Supplementary Text 3 .

\section{Health Care Resource Utilization}

HCRU events were included from the index date until the earliest of: the end of the study period, disenrollment from the database, or death. All-cause HCRU are described as rates per $100 \mathrm{PY}$. The rates and $95 \% \mathrm{CIs}$ were estimated by fitting a negative binomial model. As the results showed non-normality, the Wilcoxon rank-sum test was used to compare HCRU between the asthma+/pertussis + and asthma+/pertussis- cohorts. To account for multiple testing across time points and endpoints, the threshold for statistical significance was set at $p<0.001$. All $p$-values $<0.05$ but $\geq 0.001$ were considered suggestive of a trend.

\section{Direct Medical Costs}

DMC were compared between the asthma+/pertussis + and asthma+/pertussis- cohorts at baseline and around the index date using the Wilcoxon rank-sum test, with the same significance thresholds as for HCRU.
Excess DMC among asthma+/pertussis + vs asthma +/pertussis- comparators during months -1 to +11 around index were estimated using a generalized linear model (GLM) analysis. The model used a log link, and normal, gamma, and Tweedie distributions were tested. Total DMC in primary and secondary care was used as the dependent variable, with log-years as an offset; no additional covariates were included in the model. The threshold for statistical significance for the GLM result was set at $p<0.05$.

\section{Results}

\section{Reported Incidence Rate}

Among 687,105 patients aged $\geq 50$ years with a diagnosis of asthma, who contributed 3.6 million PY of follow-up (PYFU), 346 had a pertussis diagnosis. The overall incidence rate of pertussis was 9.6 per 100,000 PYFU (95\% CI 8.6-10.7) and was highest in 2012 (20.9; 95\% CI 16.426.2) (Figure 2). The pertussis incidence rate was highest among those aged 50-54 years (15.7 per 100,000 PYFU; 95\% CI 12.9-18.9) and appeared to decrease with increasing age (Figure 2).

\section{Health Care Resource Utilization}

The 314 asthma+/pertussis + patients who met the inclusion criteria for this part of the study were matched (1:4) with 1256 asthma+/pertussis- individuals. The baseline characteristics of the asthma + /pertussis + and asthma

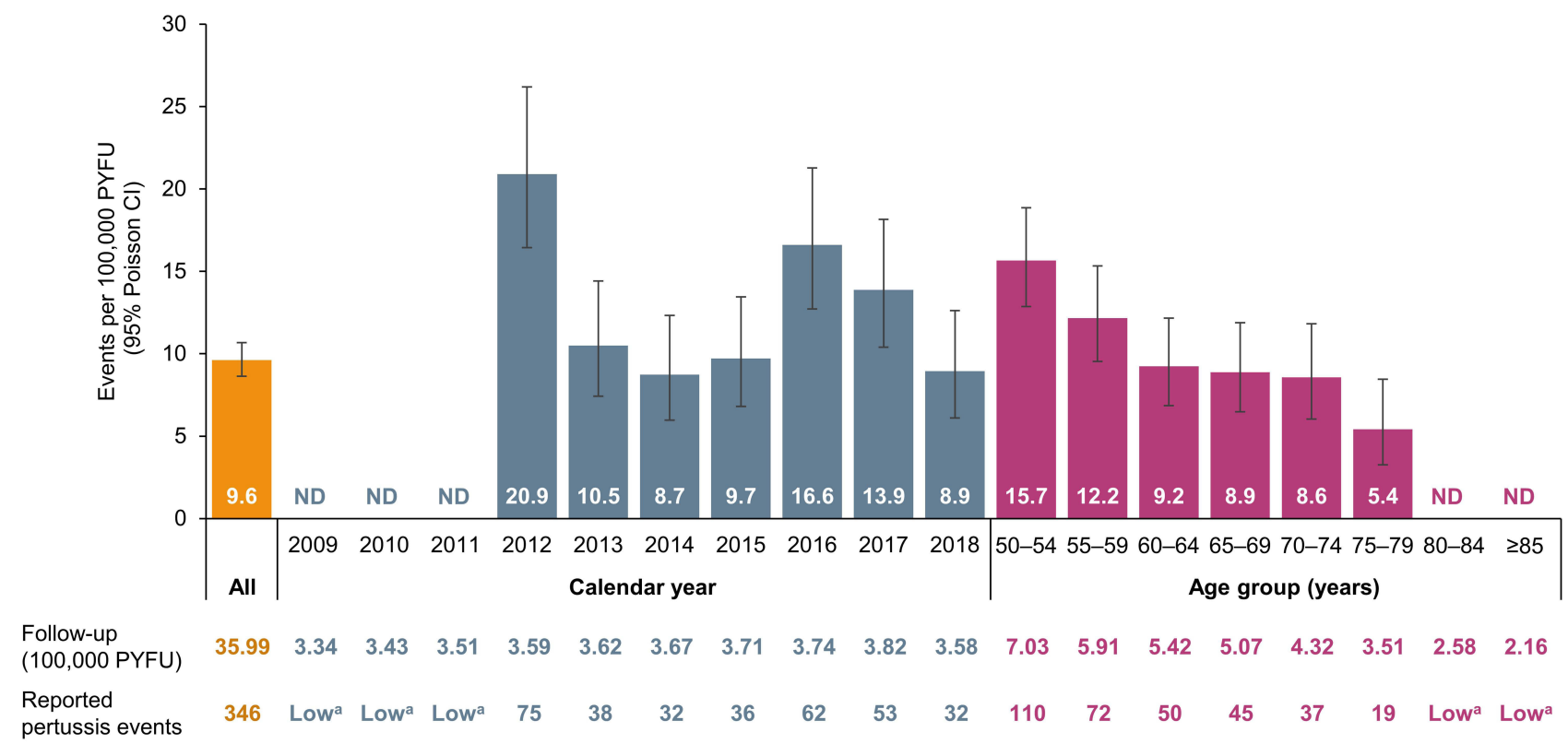

Figure 2 Incidence rate of reported pertussis among individuals with a diagnosis of asthma: overall, by calendar year, and by age group.

Notes: ${ }^{\mathrm{a} C e l l}$ counts of I-4, blinded as per Clinical Practice Research Datalink policy.

Abbreviations: $\mathrm{Cl}$, confidence interval; ND, not displayed (due to low counts); PYFU, person-years of follow-up. 
+/pertussis- cohorts were generally well balanced, apart from a higher prevalence of chronic/persistent cough in the asthma+/pertussis + cohort (Table 1). DMC during baseline were also well matched in the two cohorts (Table 1).

During months -6 to -1 before the index date, the rates of GP/nurse and A\&E visits were significantly higher (1.3and 1.7-fold, respectively) in the asthma+/pertussis + cohort than in the asthma+/pertussis- cohort (Table 2). GP/nurse visits (3.1-fold [4176 vs 1335 per $100 \mathrm{PY}$; equivalent to 3.5 vs 1.1 visits per patient per month]) and A\&E visits (4.3-fold) were also significantly higher in the asthma + /pertussis + cohort during the month before the index date, as were prescriptions (1.3-fold [5.3 vs 4.1 per patient per month]) and clinical assessments (2.7-fold [9.3 vs 3.4 per patient per month]) (Table 2 and Figure 3A). During the 2 months from the index date, GP/ nurse visits (2.0-fold [2.0 vs 1.0 per patient per month]) and clinical assessments (1.2-fold) remained significantly higher in the asthma+/pertussis + cohort, with a trend towards an increase in hospitalizations (1.4-fold) (Table 2 and Figure 3B). During months 2 to 5 after the index date, $\mathrm{GP} /$ nurse visits remained significantly elevated in the asthma+/pertussis + cohort (1.2-fold), along with a trend towards an increase in outpatient specialist visits (1.2-fold) (Table 2). At 5 to 11 months after the index date, HCRU was similar in both cohorts, apart from a trend for more $\mathrm{GP} /$ nurse visits in the asthma + /pertussis + cohort (Table 2).

Considerably more patients in the asthma + /pertussis + vs asthma+/pertussis- cohorts had $\geq 1$ A\&E visit during months -6 to -1 before index $(17.8 \%$ vs $10.3 \%$; Supplementary Table 9). In the month before index, many more patients in the asthma+/pertussis + cohort had $\geq 1 \mathrm{GP} /$ nurse visit $(87.6 \%$ vs $48.1 \%), \geq 1$ GP prescription (86.3\% vs $64.3 \%), \geq 1$ clinical assessment $(69.1 \%$ vs $27.9 \%)$, and $\geq 1 \quad$ A\&E visit $(8.9 \%$ vs $2.2 \%$; Supplementary Table 9).

There were also some significant differences in the use of the five most common prescriptions (in the asthma + pertussis + cohort) during the different time periods. During months -6 to -1 before the index date, prescription rates for oral prednisolone $5 \mathrm{mg}$ (98 vs 42 per 100 $\mathrm{PY}$ ) and amoxicillin $500 \mathrm{mg}$ (78 vs 30 per $100 \mathrm{PY}$ ) (both $p<0.001)$ were higher in the asthma + /pertussis + vs asthma +/pertussis- cohorts, with $24.5 \%$ of patients in the asthma + pertussis + cohort receiving amoxicillin (Table 3). During the month before index, prescription rates were higher in the asthma + /pertussis + vs asthma + /pertussiscohort for oral prednisolone $5 \mathrm{mg}$ (314 vs 41 per 100
PY), clarithromycin $500 \mathrm{mg}$ (225 vs 10 per $100 \mathrm{PY}$ ), salbutamol $100 \mu \mathrm{g} / \mathrm{dose}$ (194 vs 109 per $100 \mathrm{PY}$ ), and omeprazole $20 \mathrm{mg}$ (260 vs 150 per $100 \mathrm{PY}$ ) (all $p<0.001)$. During the 2 months from index, clarithromycin prescriptions remained significantly elevated (83 vs 12 per 100 PY; $p<0.001$ ) (Table 3). Clarithromycin was prescribed to $16.9 \%$ vs $0.8 \%$ and $14.0 \%$ vs $1.8 \%$ of patients in the asthma + /pertussis + vs asthma + /pertussis- cohorts during the month before and the 2 months from index, respectively (Table 3).

There were also significant differences in the five most common outpatient services visited (in the asthma+/pertussis + cohort) between the asthma + pertussis + and asthma + /pertussis- cohorts, namely diagnostic imaging (58 vs 11 per $100 \mathrm{PY}$ ) and ear, nose, and throat (43 vs 9 per $100 \mathrm{PY}$ ) during the month before index; and thoracic medicine during months 2 to 5 (39 vs 12 per $100 \mathrm{PY}$ ) and 5 to 11 (23 vs 9 per $100 \mathrm{PY}$ ) after index (all $p<0.001$, data not shown). No significant differences were observed at other timepoints, although there were trends towards increases in cardiology (during months -6 to $-1,2$ to 5 , and 5 to 11), thoracic medicine (months -1 to 0 and 0 to 2), ear, nose, and throat (months 0 to 2), and diagnostic imaging (months 2 to 5) (data not shown).

Descriptive monthly HCRU data are presented in Figure 4 . In the asthma+/pertussis + cohort, GP/nurse visits started to increase around 3 months before index (pertussis diagnosis), peaked at 3.4 visits per patient during the month before index (vs 1.1 visits per patient in the asthma+/pertussis- cohort), and remained elevated until around 3 months after index (Figure 4A). GP prescriptions also started to increase around 3 months before index and peaked at 5.3 per patient during the month before index (vs 4.0 per patient in the asthma+/pertussis- cohort) (Figure 4B). Outpatient specialist visits varied by month in both cohorts, with no obvious increase around the pertussis diagnosis (Figure 4C). However, A\&E visits started to increase from 4 months before index and peaked 1 month before index, at which time they were 4.3 -fold those in the asthma+/pertussis- cohort (Figure 4D), while hospitalizations peaked during months -2 to -1 (Figure 4E). Of note, HCRU in the asthma+/pertussiscohort remained relatively stable throughout the study.

\section{Direct Medical Costs}

Annualized per patient DMC are shown in Figure 5 and Supplementary Table 10. During months -6 to -1 , total annualized DMC were statistically significantly higher in 
Table I Baseline Demographic and Clinical Characteristics for the Matched Cohorts

\begin{tabular}{|c|c|c|c|c|}
\hline & $\begin{array}{l}\text { Asthma+/Pertussis+ Cohort } \\
(n=3 \mid 4)\end{array}$ & $\begin{array}{l}\text { Asthma+/Pertussis- Cohort } \\
(n=\mid 256)\end{array}$ & SMD & p-value \\
\hline Data source, n (\%) & & & 0.01 & 0.863 \\
\hline Aurum & $285(90.8)$ & $1136(90.4)$ & & \\
\hline GOLD & $29(9.2)$ & $120(9.6)$ & & \\
\hline Age at index date, years, mean (SD) & $61(9)$ & $61(9)$ & 0.02 & 0.575 \\
\hline$\geq 65$ years, $\mathrm{n}(\%)$ & $98(3 \mid .2)$ & $403(32.1)$ & 0.02 & 0.787 \\
\hline Female, n (\%) & $194(61.8)$ & $763(60.7)$ & 0.02 & 0.747 \\
\hline Ethnicity, n (\%) & $n=269$ & $n=1023$ & - & 0.686 \\
\hline White & $258(95.9)$ & $965(94.3)$ & & \\
\hline Asian & $6(2.2)$ & $31(3.0)$ & & \\
\hline Black & Low $^{a}$ & $12(1.2)$ & & \\
\hline Mixed & Low $^{\mathrm{a}}$ & $5(0.5)$ & & \\
\hline Other & Low $^{a}$ & $10(1.0)$ & & \\
\hline Year of index date, n (\%) & & & - & 0.898 \\
\hline 2009 & Low $^{a}$ & $14(\mathrm{I} . \mathrm{I})$ & & \\
\hline 2010 & Low $^{a}$ & $13(1.0)$ & & \\
\hline 2011 & $7(2.2)$ & $18(1.4)$ & & \\
\hline 2012 & $72(22.9)$ & $292(23.2)$ & & \\
\hline 2013 & $36(11.5)$ & III (8.8) & & \\
\hline 2014 & $28(8.9)$ & $114(9.1)$ & & \\
\hline 2015 & $34(10.8)$ & $143(\mid 1.4)$ & & \\
\hline 2016 & $55(17.5)$ & $245(19.5)$ & & \\
\hline 2017 & $49(15.6)$ & $206(16.4)$ & & \\
\hline 2018 & $24(7.6)$ & $100(8.0)$ & & \\
\hline Season, n (\%) & & & - & 0.466 \\
\hline Spring (March-May) & $64(20.4)$ & $233(18.6)$ & & \\
\hline Summer (June-August) & $78(24.8)$ & $330(26.3)$ & & \\
\hline Autumn (September-November) & III (35.4) & $485(38.6)$ & & \\
\hline Winter (December-February) & $61(19.4)$ & $208(16.6)$ & & \\
\hline IMD, n (\%) & & & - & 0.853 \\
\hline Quintile I & $105(33.4)$ & $463(36.9)$ & & \\
\hline Quintile 2 & $77(24.5)$ & $275(21.9)$ & & \\
\hline Quintile 3 & $67(2 \mid .3)$ & $220(17.5)$ & & \\
\hline Quintile 4 & $44(14.0)$ & $176(14.0)$ & & \\
\hline Quintile 5 & $21(6.7)$ & $122(9.7)$ & & \\
\hline Smoking status, ${ }^{\mathrm{b}}$ (\%) & $n=204$ & $n=803$ & - & 0.953 \\
\hline Current & $48(23.5)$ & $192(23.9)$ & & \\
\hline Past & $102(50.0)$ & $407(50.7)$ & & \\
\hline Never & $54(26.5)$ & $204(25.4)$ & & \\
\hline BMI, ${ }^{c} \mathrm{~kg} / \mathrm{m}^{2}$, mean $(\mathrm{SD})$ & $30(6)(n=194)$ & $30(6)(n=757)$ & $<0.01$ & 0.849 \\
\hline Obese, ${ }^{d}$ n (\%) & $88(28.0)$ & $341(27.1)$ & 0.02 & 0.777 \\
\hline \multicolumn{5}{|l|}{ Most common health conditions, ${ }^{\mathrm{e}} \mathrm{n}(\%)$} \\
\hline Hypertension & $113(36.0)$ & $474(37.7)$ & 0.04 & 0.602 \\
\hline Depression & $78(24.8)$ & $313(24.9)$ & $<0.01$ & $>0.999$ \\
\hline Hyperlipidemia & $58(18.5)$ & $249(19.8)$ & 0.03 & 0.633 \\
\hline Diabetes mellitus & $46(14.6)$ & $215(17.1)$ & 0.07 & 0.310 \\
\hline
\end{tabular}

(Continued) 
Table I (Continued).

\begin{tabular}{|c|c|c|c|c|}
\hline & $\begin{array}{l}\text { Asthma+/Pertussis+ Cohort } \\
(n=3 \mid 4)\end{array}$ & $\begin{array}{l}\text { Asthma+/Pertussis- Cohort } \\
(n=1256)\end{array}$ & SMD & p-value \\
\hline COPD & $38(12.1)$ & $169(13.5)$ & 0.04 & 0.576 \\
\hline Malignant cancer & $35($ (II.I) & $156(12.4)$ & 0.04 & 0.629 \\
\hline GERD & $33(10.5)$ & $85(6.8)$ & 0.13 & 0.031 \\
\hline Chronic/persistent cough & $36(11.5)$ & $72(5.7)$ & 0.21 & $<0.001$ \\
\hline Asthma-related hospitalizations, ${ }^{\mathrm{f}} \mathrm{n}(\%)$ & & & 0.03 & 0.564 \\
\hline 0 & Low $^{a}$ & Low $^{a}$ & & \\
\hline I & Low $^{a}$ & Low $^{a}$ & & \\
\hline$\geq 2$ & $0(0.0)$ & $0(0.0)$ & & \\
\hline $\mathrm{FEV}_{1},{ }^{\mathrm{c}} \mathrm{n}(\%)$ & $n=28$ & $n=105$ & - & 0.071 \\
\hline$\geq 80 \%$ predicted & $15(53.6)$ & $35(33.3)$ & & \\
\hline $50 \%$ to $<80 \%$ predicted & $10(35.7)$ & $53(50.5)$ & & \\
\hline $30 \%$ to $<50 \%$ predicted & Low $^{\mathrm{a}}$ & Low $^{a}$ & & \\
\hline$<30 \%$ predicted & Low $^{a}$ & Low $^{a}$ & & \\
\hline $\begin{array}{l}\text { Treatment corresponding to asthma GINA step } \\
4 / 5,{ }^{8} \mathrm{n}(\%)\end{array}$ & $49(15.6)$ & $198(15.8)$ & $<0.01$ & $>0.999$ \\
\hline Pertussis vaccine in past 10 years, $n$ (\%) & $0(0.0)$ & $0(0.0)$ & - & - \\
\hline $\mathrm{DMC}^{\mathrm{h}} \in$, mean $(\mathrm{SD})$ & | $497(273 \mid)$ & 1409 (2389) & 0.03 & 0.200 \\
\hline
\end{tabular}

Notes: "Low" indicates cell counts of $\mathrm{I}-4$, blinded as per Clinical Practice Research Datalink policy. If only one event count in a stratification block was I-4 and a total is given, the next lowest non-zero event count is marked "low" to prevent identification of any exact cell count of $I-4$. 'Most recent record from -18 months to before -6 months. "Most recent record during the 18 months before the index date. ${ }^{d}$ Most recent BMI $\geq 30 \mathrm{~kg} / \mathrm{m}^{2}$ during the 18 months before the index date, or obesity in the clinical record during the 18 months before the index date (and no subsequent BMl $<30 \mathrm{~kg} / \mathrm{m}^{2}$ before the index date). ${ }^{\mathrm{e}} \mathrm{At}$ any time before the index date. ${ }^{\mathrm{f}} \mathrm{Number}$ of hospitalizations for $\geq \mathrm{I}$ night with a primary diagnosis code of asthma, excluding admissions $<14$ days after a previous admission, during the 18 months before the index date. ${ }^{\mathrm{g}} \mathrm{A}$ prescription for a medium- or high-dose inhaled corticosteroid/long-acting beta 2 agonist combination during the 18 months before the index date. ${ }^{\mathrm{h}} \mathrm{Baseline} \mathrm{DMC}$ included costs for general practitioner/nurse, outpatient specialist, and accident and emergency visits, and inpatient stays from -18 months to before -6 months.

Abbreviations: asthma+/pertussis+, patients with diagnoses of asthma and pertussis; asthma+/pertussis-, patients with a diagnosis of asthma without pertussis; BMI, body mass index; COPD, chronic obstructive pulmonary disease; DMC, direct medical costs; FEV , forced expiratory volume in I second; GINA, Global Initiative for Asthma; GERD, gastroesophageal reflux disease; IMD, Index of Multiple Deprivation; n, number of people; SD, standard deviation; SMD, standardized mean difference.

the asthma+/pertussis + vs asthma+/pertussis- cohorts by the Wilcoxon rank-sum test $(p<0.001)$ although mean values were numerically similar. During the month before the index date, mean total annualized DMC per patient were $£ 1362$ higher in the asthma+/pertussis + cohort $(p<0.001)$, predominantly due to a $£ 1014$ increase for GP/nurse visits, but also a $£ 145$ increase for A\&E visits. During the 2 months from the index date, mean total annualized DMC per patient were $£ 833$ higher in the asthma+/pertussis + cohort $(p<0.001)$, mainly due to $£ 448$ and $£ 335$ increases for GP/ nurse visits and hospitalizations, respectively. Annualized DMC remained significantly elevated in the asthma+/pertussis + cohort during months 2 to 5 , but beyond 5 months after the index date, they were statistically similar in the two cohorts. The total annualized DMC per patient in the asthma + /pertussis + vs asthma + pertussis- cohorts during months -1 to +11 months were $£ 1825$ vs $£ 1404(p<0.001)$.

\section{Generalized Linear Model Results}

The Tweedie model distribution was selected for the regression analysis as it was the only one to converge due to the skewness of the data and existence of zero values. $^{35}$ The total estimated DMC increase per patient in the asthma+/pertussis + vs asthma+/pertussis- cohorts during months -1 to +11 months was $£ 370$ (95\% CI 128-650; 26.4\% higher; $p=0.002$ ).

\section{Discussion}

Using data from the merged CPRD Aurum and GOLD databases, we estimated the incidence rate of reported pertussis among individuals aged $\geq 50$ years with a diagnosis of asthma to be 9.6 events per 100,000 PYFU in England during 2009-2018, with a peak of 20.9 in 2012. This is approximately twice as high as the estimated incidence rate among a general cohort of adults 
Table 2 Rates of HCRU per 100 PY $(95 \% \mathrm{Cl})$ in the Asthma+/Pertussis+ and Asthma+/Pertussis- Cohorts During Predefined Periods from -6 Months to + II Months Around the Index Date

\begin{tabular}{|c|c|c|c|c|c|}
\hline & -6 to -1 Month & -I Month to Index & Index to 2 Months & 2 to 5 Months & 5 to II Months \\
\hline \multicolumn{6}{|l|}{ GP/nurse } \\
\hline Asthma+/pertussis+ & $1593^{\mathrm{a}}(1442-1760)$ & $4176^{a}(3838-4544)$ & $2446^{a}(2262-2644)$ & $145 I^{\mathrm{a}}(1297-1624)$ & $1264^{\mathrm{b}}(1142-1398)$ \\
\hline Asthma+/pertussis- & $1226(1153-1304)$ & 1335 (|226-1453) & $\mid 207(|| 2|-| 300)$ & $1206(1130-1288)$ & $1200(|| 3 \mid-1274)$ \\
\hline \multicolumn{6}{|l|}{ GP prescriptions } \\
\hline Asthma+/pertussis+ & 4748 (4208-5357) & $6405^{a}(5699-7200)$ & $5109(4492-5810)$ & 4727 (4I47-5388) & $4636(4057-5298)$ \\
\hline Asthma+/pertussis- & $4611(4301-4944)$ & $4897(4500-5330)$ & $4797(4468-5151)$ & $4620(4310-4953)$ & $4817(4495-5161)$ \\
\hline \multicolumn{6}{|l|}{ Clinical assessments } \\
\hline Asthma+/pertussis+ & $\left.399\right|^{b}(3378-47 \mid 5)$ & II, I 40 $0^{\mathrm{a}}(9258-13,403)$ & $4629^{a}(3724-5755)$ & $3969(3 \mid 48-5003)$ & 4057 (3359-490I) \\
\hline Asthma+/pertussis- & $3874(348 \mid-43 I I)$ & $4074(3388-4900)$ & $3746(3226-435 I)$ & $3595(3161-4088)$ & $3774(3424-4160)$ \\
\hline \multicolumn{6}{|l|}{ Outpatient specialist } \\
\hline Asthma+/pertussis+ & 271 (223-329) & $357(280-455)$ & $290(229-366)$ & $315^{\mathrm{b}}(256-387)$ & 279 (223-349) \\
\hline Asthma+/pertussis- & $282(252-315)$ & $292(253-336)$ & $274(24|-3| 2)$ & 259 (229-292) & 266 (237-299) \\
\hline \multicolumn{6}{|l|}{ A\&E } \\
\hline Asthma+/pertussis+ & $59^{a}(45-77)$ & $128^{a}(87-\mid 87)$ & $55(36-82)$ & $34(23-5 I)$ & $31(22-43)$ \\
\hline Asthma+/pertussis- & $34(28-4 I)$ & $30(21-44)$ & $39(31-50)$ & $28(2 \mid-36)$ & $33(28-40)$ \\
\hline \multicolumn{6}{|l|}{ Hospitalizations } \\
\hline Asthma+/pertussis+ & $51(38-69)$ & $74(43-128)$ & $6 I^{b}(4 I-90)$ & $50(35-73)$ & $33(22-47)$ \\
\hline Asthma+/pertussis- & $52(43-62)$ & $44(32-60)$ & $42(33-55)$ & $40(32-50)$ & $48(40-57)$ \\
\hline
\end{tabular}

Notes: Data are events per $100 \mathrm{PY}(95 \% \mathrm{Cl})$ estimated by fitting a negative binomial model. ${ }^{\text {a }}$ Uncorrected $p<0.00 \mathrm{I}$ vs the asthma $+/$ pertussis- cohort (statistically significant after cut-off adjustment for multiplicity) are displayed in bold. buncorrected $p<0.05$ vs the asthma+/pertussis- cohort (suggestive of a trend).

Abbreviations: A\&E, accident and emergency; asthma+/pertussis+, patients with diagnoses of asthma and pertussis; asthma+/pertussis-, patients with a diagnosis of asthma without pertussis; $\mathrm{Cl}$, confidence interval; GP, general practitioner; HCRU, health care resource utilization; PY, person-years.

aged $\geq 50$ years in England in a study that used the same methodology across the same time period (5.8 events per 100,000 PYFU; 12.4 in 2012). ${ }^{36}$ The cyclic nature of the yearly estimated incidence rates among older adults with a diagnosis of asthma in the current study were well aligned with the pertussis cases reported by Public Health England, ${ }^{6}$ including the pertussis outbreak in England in 2012 (laboratory confirmed cases: 18 per 100,000 overall; ${ }^{6}$ notifications: approximately 7 per 100,000 in those aged $\geq 45$ years). ${ }^{5,37}$ We also observed that the incidence rate of diagnosed pertussis declined with increasing age, possibly related to reduced exposure or increased under-recognition of pertussis among older adults. $^{14}$

In the current study, patients in the asthma+/pertussis + cohort had increased HCRU compared to those in the asthma+/pertussis- cohort, highlighting the clinical implications of pertussis infection among those with a diagnosis of asthma. Underlying this increase may be a combination of pertussis diagnosis and treatment of exacerbated asthma symptoms. In a Canadian study, asthma symptoms worsened in individuals with pertussis, as reflected by increased bronchodilator use in $>90 \%$ of patients with preexisting pulmonary disease (mainly asthma). ${ }^{3}$ Those with vs without asthma also had a longer mean duration of paroxysmal cough and more nights disturbed by pertussis. ${ }^{3}$ In a US study, all-cause and pertussis-related hospitalization and health care expenses were higher in patients with diagnoses of asthma and pertussis than in those with pertussis alone. ${ }^{21}$ The present data add to the consensus that pertussis has a substantial impact in people with asthma.

In the current study, GP/nurse visits, GP prescriptions, A\&E visits, and hospitalizations started to increase in the asthma + /pertussis + cohort from approximately 3 months before a pertussis diagnosis. This indicates that patients may seek medical care for symptoms well in advance of being diagnosed with pertussis, ${ }^{16}$ which is in line with a typical cough duration of 3 months. ${ }^{3}$ In the asthma+/pertussis + vs asthma + /pertussis- cohort during months -6 to -1 , there were significantly more prescriptions for oral prednisolone - which is recommended for asthma exacerbations ${ }^{38}$ - and amoxicillin - which is known to be prescribed for patients with asthma and lower respiratory tract infections 
Asthma+/pertussis+
Asthma+/pertussis-

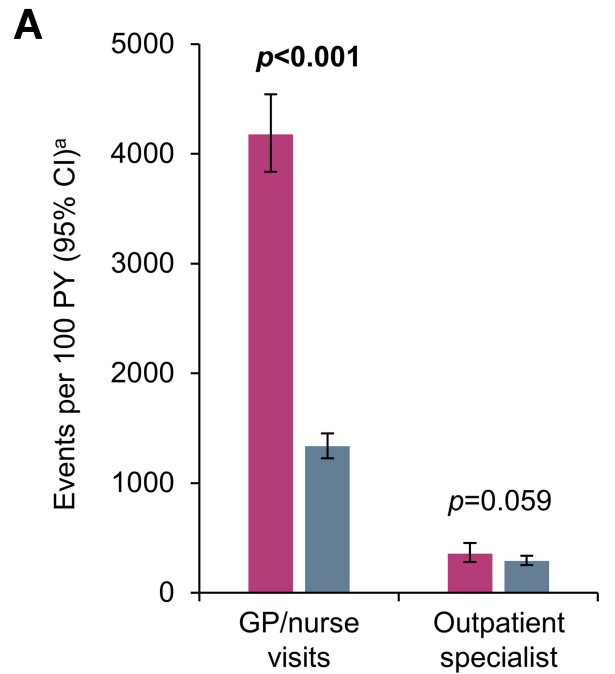

B

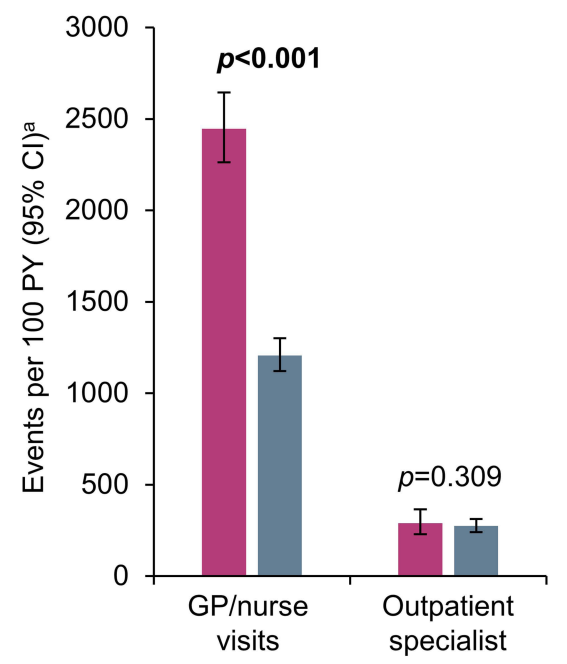

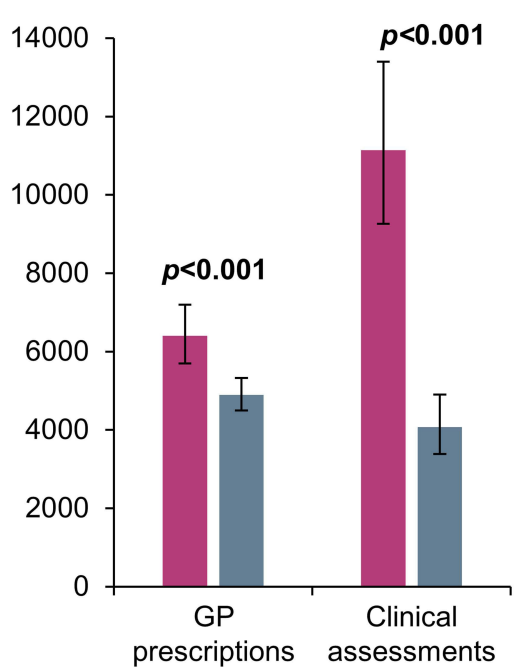

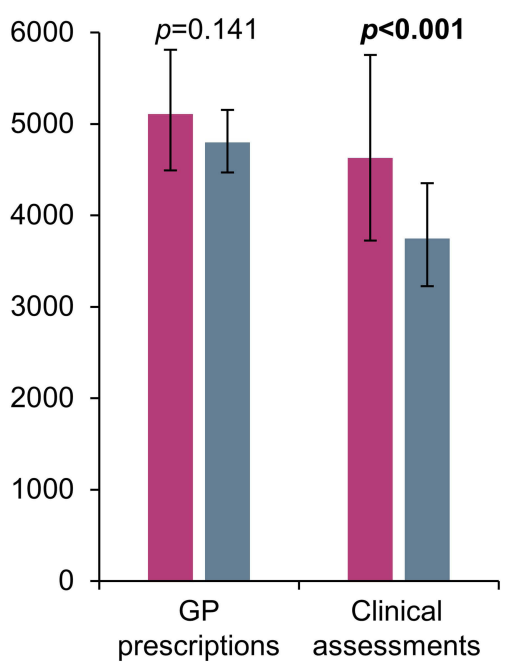

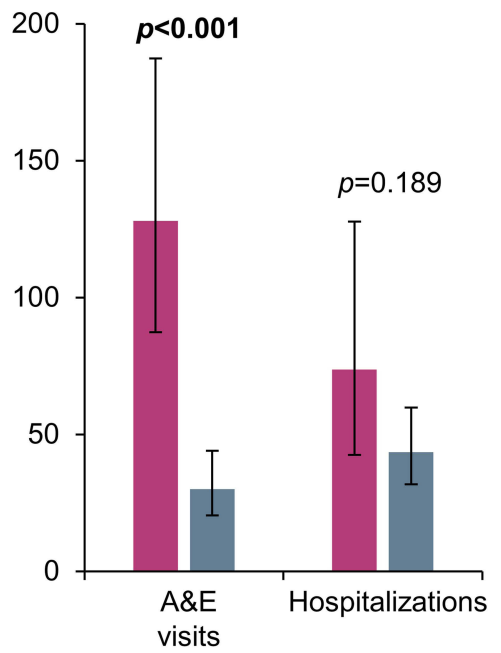

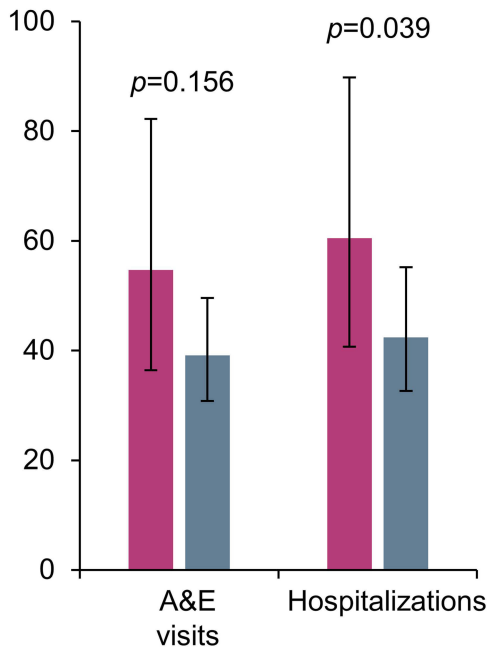

Figure $3 \mathrm{HCRU}$ per $100 \mathrm{PY}$ in the asthma+/pertussis+ and asthma+/pertussis- cohorts during (A) $-\mathrm{I}$ month to index and (B) index to 2 months.

Notes: ${ }^{a}$ Event rates and $95 \% \mathrm{Cls}$ were estimated by fitting a negative binomial model. Uncorrected $p<0.00 \mathrm{I}$ is displayed in bold and indicates statistical significance after cutoff adjustment for multiplicity. Uncorrected $p<0.05$ is suggestive of a trend.

Abbreviations: A\&E, accident and emergency; asthma+/pertussis+, patients with diagnoses of asthma and pertussis; asthma+/pertussis-, patients with a diagnosis of asthma without pertussis; Cl, confidence interval; GP, general practitioner; HCRU, health care resource utilization; PY, person-years.

(LRTIs), ie infective asthma exacerbations. ${ }^{39}$ In the month before a pertussis diagnosis, there were significant excesses in the use of prednisolone and salbutamol - suggesting nonresolving asthma symptoms - and clarithromycin - which is one of the antibiotics recommended for people with suspected or confirmed pertussis, ${ }^{40}$ but is also a second-line antibiotic for patients with asthma and LRTIs. ${ }^{39}$ Omeprazole prescriptions were also increased, but only in the asthma + /pertussis + cohort, possibly indicating symptom overlap between pertussis and gastroesophageal reflux disease. ${ }^{41}$ Prescriptions for clarithromycin were also significantly elevated during the 2 months from diagnosis. Although it should be noted that we only analyzed the top five prescriptions (in the asthma+/pertussis + cohort during each time period), this treatment pattern suggests that it often took time to arrive at a pertussis diagnosis, during which time patients may have been experiencing acute exacerbations of asthma and/or have been treated for an LRTI (whether misdiagnosed pertussis, another LRTI, or coinfection). A study in the US has also reported that some children with pertussis were originally misdiagnosed with an asthma exacerbation, ${ }^{42}$ while a Chinese study reported $B$. pertussis in 
Table 3 Use of the Five Most Common Prescriptions (in the Asthma+/Pertussis+ Cohort During Each Time Period) in the Asthma $+/$ Pertussis+ and Asthma+/Pertussis- Cohorts During Each Time Period Around the Index Date

\begin{tabular}{|c|c|c|c|c|c|c|c|c|c|c|}
\hline & \multicolumn{2}{|c|}{-6 to -1 Month } & \multicolumn{2}{|c|}{-I Month to Index } & \multicolumn{2}{|c|}{ Index to 2 Months } & \multicolumn{2}{|c|}{2 to 5 Months } & \multicolumn{2}{|c|}{5 to II Months } \\
\hline & $\%$ & $\begin{array}{l}\text { Rate per } 100 \\
\text { PY }(95 \% \mathrm{Cl})\end{array}$ & $\%$ & $\begin{array}{l}\text { Rate per } 100 \\
\text { PY }(95 \% \mathrm{Cl})\end{array}$ & $\%$ & $\begin{array}{l}\text { Rate per } 100 \\
\text { PY }(95 \% \mathrm{Cl})\end{array}$ & $\%$ & $\begin{array}{l}\text { Rate per } 100 \\
\text { PY }(95 \% \mathrm{Cl})\end{array}$ & $\%$ & $\begin{array}{l}\text { Rate per } 100 \\
\text { PY }(95 \% \mathrm{Cl})\end{array}$ \\
\hline \multicolumn{11}{|l|}{$\begin{array}{l}\text { Salbutamol } 100 \mu \mathrm{g} / \text { dose } \\
\text { inhaler CFC free }\end{array}$} \\
\hline Asthma+/pertussis + & 22.6 & $119(89-158)$ & 14.6 & $\begin{array}{l}194^{\mathrm{a}, \mathrm{b}}(144- \\
256)\end{array}$ & 16.6 & $134^{c}(100-178)$ & 14.5 & $108(76-152)$ & 16.5 & $98(67-143)$ \\
\hline Asthma+/pertussis- & 17.7 & $97(82-115)$ & 7.6 & $109(88-134)$ & 11.4 & $101(84-121)$ & 12.9 & $98(81-119)$ & 18.2 & $97(82-116)$ \\
\hline \multicolumn{11}{|l|}{$\begin{array}{l}\text { Ventolin (GSK) } 100 \mu \mathrm{gg} / \\
\text { dose Evohaler (GSK) }\end{array}$} \\
\hline Asthma+/pertussis+ & 21.7 & $116(87-156)$ & 14.0 & $194^{b, c}(144-256)$ & 13.7 & $124(89-174)$ & 16.4 & $112(82-154)$ & 21.8 & $109(80-148)$ \\
\hline Asthma+/pertussis- & 20.6 & $122(104-142)$ & 8.9 & $121(101-146)$ & 13.3 & $113(95-133)$ & 16.4 & $118(100-138)$ & 21.6 & $115(98-134)$ \\
\hline Prednisolone $5 \mathrm{mg}$ tablets & & & & & & & & & & \\
\hline Asthma+/pertussis+ & 25.8 & $98^{a}(78-124)$ & 20.7 & $\begin{array}{l}314^{\mathrm{a}}(247- \\
400)\end{array}$ & NA & NA & NA & NA & NA & NA \\
\hline Asthma+/pertussis- & 9.1 & $42(33-53)$ & 2.8 & $41(29-58)$ & NA & NA & NA & NA & NA & NA \\
\hline \multicolumn{11}{|l|}{$\begin{array}{l}\text { Amoxicillin } 500 \text { mg } \\
\text { capsules }\end{array}$} \\
\hline Asthma+/pertussis+ & 24.5 & $78^{a}(63-98)$ & NA & NA & NA & NA & NA & NA & NA & NA \\
\hline Asthma+/pertussis- & 9.4 & $30^{\mathrm{b}}(26-35)$ & NA & NA & NA & NA & NA & NA & NA & NA \\
\hline \multicolumn{11}{|l|}{$\begin{array}{l}\text { Clarithromycin } 500 \mathrm{mg} \\
\text { tablets }\end{array}$} \\
\hline Asthma+/pertussis+ & NA & NA & 16.9 & $\begin{array}{l}225^{a}(174- \\
291)\end{array}$ & 14.0 & $83^{a}(62-111)$ & NA & NA & NA & NA \\
\hline Asthma+/pertussis- & NA & NA & 0.8 & $10^{\mathrm{b}}(5-18)$ & 1.8 & $12(8-18)$ & NA & NA & NA & NA \\
\hline \multicolumn{11}{|l|}{$\begin{array}{l}\text { Omeprazole } 20 \mathrm{mg} \\
\text { gastro-resistant capsules }\end{array}$} \\
\hline Asthma+/pertussis + & 23.6 & $171^{c}(126-232)$ & 17.5 & $\begin{array}{l}260^{\mathrm{a}}(198- \\
341)\end{array}$ & 16.9 & $195(|40-27|)$ & 18.0 & $164(118-228)$ & 20.8 & $176(122-253)$ \\
\hline Asthma+/pertussis- & 17.8 & $142(|| 8-|7|)$ & 10.4 & $150(126-180)$ & 13.9 & $151(126-180)$ & 15.2 & $147(122-176)$ & 17.9 & $156(128-190)$ \\
\hline \multicolumn{11}{|l|}{ Bendroflumethiazide } \\
\hline $2.5 \mathrm{mg}$ tablets & & & & & & & & & & \\
\hline Asthma+/pertussis+ & NA & NA & NA & NA & 6.7 & $98(54-176)$ & 7.4 & $94(52-169)$ & 6.9 & $85(4 I-176)$ \\
\hline Asthma+/pertussis- & NA & NA & NA & NA & 6.4 & $56(43-72)$ & 6.7 & $6 I(46-8 I)$ & 6.7 & $61(43-85)$ \\
\hline \multicolumn{11}{|l|}{$\begin{array}{l}\text { Paracetamol } 500 \mathrm{mg} \\
\text { tablets }\end{array}$} \\
\hline Asthma+/pertussis+ & NA & NA & NA & NA & NA & NA & 9.3 & $89(55-145)$ & 11.6 & $93(56-155)$ \\
\hline Asthma+/pertussis- & NA & NA & NA & NA & NA & NA & 8.3 & $67(52-85)$ & 10.5 & $72(56-93)$ \\
\hline
\end{tabular}

Notes: Data are \% of patients and rates of prescriptions per 100 person-years $(95 \% \mathrm{Cl})$, the latter estimated by fitting a negative binomial model unless otherwise specified. ${ }^{a}$ Uncorrected $p<0.00 \mathrm{I}$ vs the asthma+/pertussis- cohort (statistically significant after cut-off adjustment for multiplicity) are displayed in bold. ${ }^{\text {b }}$ The negative binomial model could not be fitted; Poisson estimates were used instead. 'Uncorrected $p<0.05$ vs the asthma+/pertussis- cohort (suggestive of a trend).

Abbreviations: asthma+/pertussis+, patients with diagnoses of asthma and pertussis; asthma+/pertussis-, patients with a diagnosis of asthma without pertussis; CFC, chlorofluorocarbon; $\mathrm{Cl}$, confidence interval; NA, not available (as only data for the top five prescriptions in the asthma+/pertussis+ cohort in each time period were compiled).

nasopharyngeal swabs from $28 \%$ of children with acute asthma exacerbations. ${ }^{43}$

During the 5 months from a pertussis diagnosis, some HCRU continued to be elevated, suggesting medical follow-up. Overall, the study indicates an increased need for
HCRU and a lengthy time to diagnosis, which is concerning given the recommendation to treat pertussis early in its course in order to help improve recovery and prevent transmission. ${ }^{44}$ The potential adverse effects of systemic corticosteroids have been highlighted by others, ${ }^{45}$ and the 

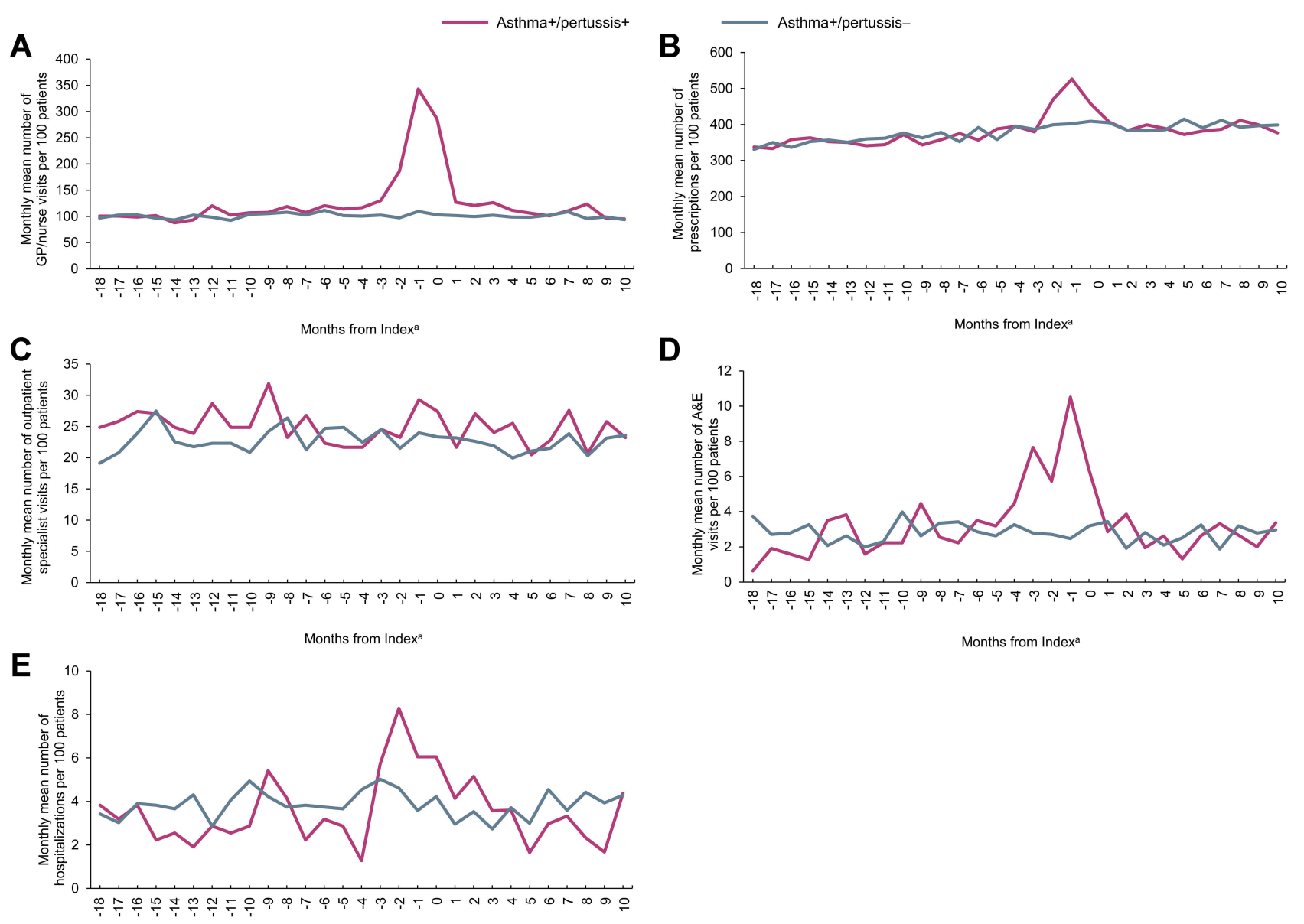

Months from Index ${ }^{a}$

Figure 4 Mean monthly ${ }^{\mathrm{a}}$ all-cause HCRU in the asthma+/pertussis+ and asthma+/pertussis- cohorts from - 18 months to II months around the index date (pertussis diagnosis): (A) GP/nurse visits; (B) GP prescriptions; (C) outpatient specialist visits; (D) A\&E visits; and (E) hospitalizations.

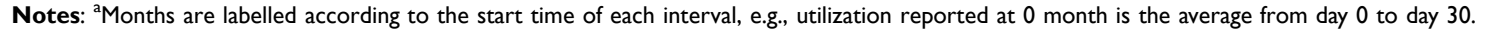

Abbreviations: A\&E, accident and emergency; asthma+/pertussis+, patients with diagnoses of asthma and pertussis; asthma+/pertussis-, patients with a diagnosis of asthma without pertussis; GP, general practitioner; HCRU, health care resource utilization .

elevated use of oral prednisolone in the asthmat/pertussis + cohort further reinforces the benefits of preventing pertussis in patients with asthma. However, further studies are required to ascertain whether pertussis prevention could reduce corticosteroid use in patients with asthma.

Patients aged $\geq 50$ years in the asthma + /pertussis + cohort had an estimated mean excess annual DMC of $£ 370$ compared to those in the asthma+/pertussis- cohort. This total cost (including diagnosis) is generally in line with the mean cost of treating a case of acute respiratory illness during influenza seasons in 2001-2009 in a general population in another CPRD study in the UK, which reported costs of $£ 116$ for those aged 50-64 years and $£ 478$ for those aged $\geq 65$ years. ${ }^{46}$

Recently, national and international organizations reinforced their adult tetanus, diphtheria, and acellular pertussis (Tdap) and other vaccine recommendations ${ }^{47-50}$ in order to maintain good health in vulnerable age groups during the COVID-19 pandemic and to reduce the burden of pertussis on healthcare systems. In the US, the Centers for Disease Control and Prevention recommends that all adults receive one dose of Tdap vaccination if not previously received at or after 11 years of age (reflected in the 2021 Global Initiative for Chronic Obstructive Lung Disease guidelines ${ }^{51}$ ) followed by 10 -yearly Tdap or tetanus-diphtheria vaccination. ${ }^{52}$ Adults are also recommended to receive various other vaccines, including those against influenza (all ages) and pneumococcal disease (age $\geq 65$ years). ${ }^{52}$ Younger adults with lung disease are also recommended to receive pneumococcal vaccination. ${ }^{52}$ In the UK, adult pertussis vaccination is recommended for pregnant women, ${ }^{53}$ and indeed, none 


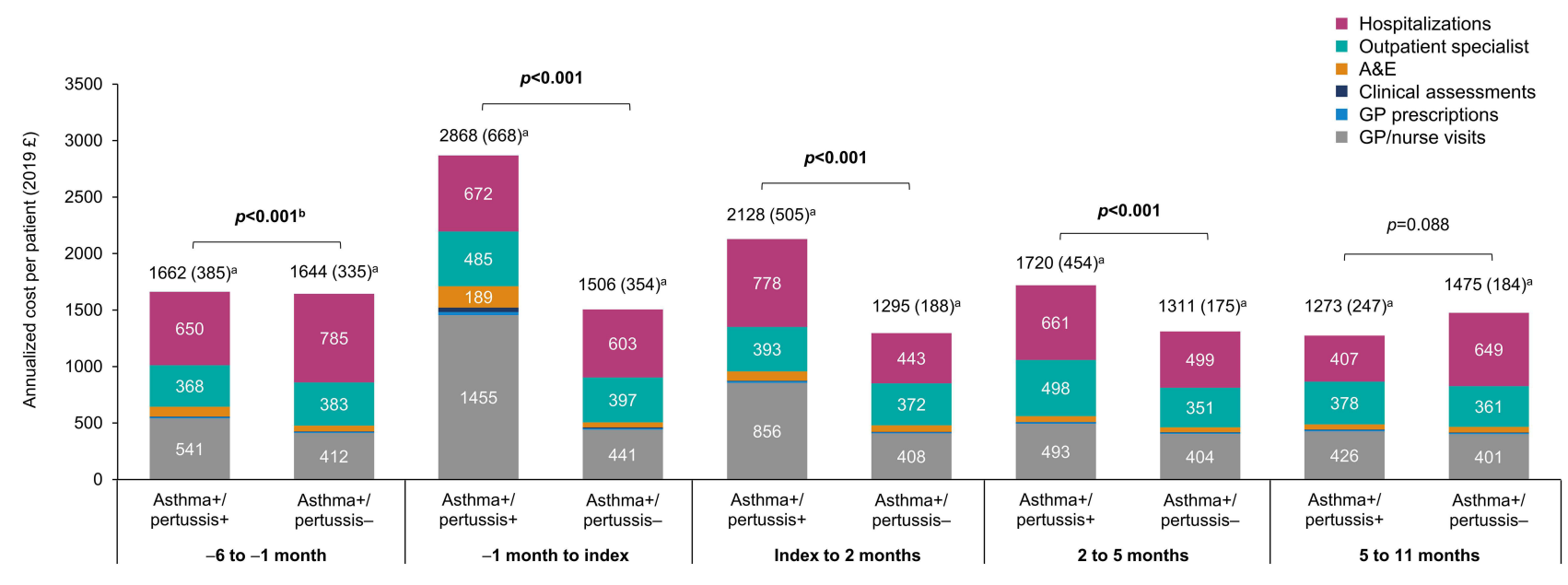

Figure 5 Annualized per-patient $\mathrm{DMC}^{\mathrm{a}}$ in the asthma+/pertussis+ and asthma+/pertussis- cohorts during the various time periods of the study.

Notes: ${ }^{a}$ Values above bars show total mean $(95 \% \mathrm{Cl})$ annualized DMC per patient. $95 \% \mathrm{Cl}$ were obtained assuming Student's $\mathrm{t}$ distribution for the annualized DMC means. Absolute mean values and standard deviations can be found in Supplementary Table I0. $p$-values were calculated using the Wilcoxon rank-sum test. Uncorrected $p<0.00 \mathrm{I}$ is displayed in bold and indicates statistical significance after cut-off adjustment for multiplicity. Unit costs for GP, nurse, and outpatient specialist visits were derived from the 2019 Unit Costs of Health and Social Care published by the Personal Social Services Research Unit from the University of Kent. ${ }^{25}$ Unit costs for the five most commonly prescribed medications (in the asthma+/pertussis+ cohort; during each time interval) were derived from the September $2019 \mathrm{NHS}$ Drug Tariff. ${ }^{26}$ Unit costs for the five most common clinical assessments and A\&E costs were derived from the 2018/2019 National Schedule of NHS Reference Costs. ${ }^{27}$ Hospitalization costs were derived using reference costs from the 2018/2019 National Schedule of NHS Reference Costs. ${ }^{27}$ b Medians were: $£ 699$ vs $£ 464$.

Abbreviations: A\&E, accident and emergency; asthma+/pertussis+, patients with diagnoses of asthma and pertussis; asthma+/pertussis-, patients with a diagnosis of asthma without pertussis; DMC, direct medical costs; Cl, confidence interval; GP, general practitioner.

of the people with a diagnosis of asthma in the current study had a record of pertussis vaccination in the previous 10 years. Currently, the only vaccinations that are additionally recommended for adults with asthma in the UK are influenza and pneumococcal vaccinations, but only for those with severe asthma (defined as "asthma that requires continuous or repeated use of inhaled or systemic steroids or with previous exacerbations requiring hospital admission" for influenza vaccination and "so severe as to require continuous or frequently repeated use of systemic steroids" for pneumococcal vaccination). ${ }^{54}$

\section{Strengths and Limitations}

Strengths of our study include the use of a large observational dataset that is generalizable to all adults with a diagnosis of asthma in England and contains demographic and clinical information data in primary and secondary care.

Using medical codes to define asthma is a limiting factor because we could not ascertain how the initial diagnosis was made nor potential concurrent diagnosis of asthma and pertussis. Using medical codes to define pertussis cases is also a limitation, as we do not know how they were diagnosed. However, our epidemiological patterns in pertussis incidence rates during 2009-2018 were well aligned with Public Health England data on laboratory confirmed pertussis cases during this period, ${ }^{6}$ bringing credence to our method. Although our incidence rates should be a reasonable approximation of laboratory confirmed pertussis, it is highly likely that the true pertussis incidence is considerably higher, as individuals who did not seek health care for their symptoms and those whose pertussis was misdiagnosed or not reported would not have been captured.

Although quality control checks were conducted, we could not assess the validity and completeness of individual patient records. Also, deprivation measures (IMD) were included in the propensity score matching, but this was estimated based on residence postcode rather than individual measures.

More patients in the asthma+/pertussis + vs asthma +/pertussis- cohort had chronic/persistent cough, with unknown underlying causes. There may also have been imbalances in unmeasured factors. However, other baseline characteristics and DMC were well balanced, and HCRU was similar apart from around the pertussis diagnosis (Figure 4), so any impact should be small. It is possible that some of the excess health care use in the asthma + /pertussis + cohort was not related to pertussis, although having a matched comparator cohort should have reduced the risk of confounding. However, we could not capture the costs of treating pertussis among 
patients with undiagnosed pertussis. Although the CPRD contains data on drug prescriptions, it does not contain information on why each drug was prescribed nor drug consumption. Also, only the top five prescription medications (in the asthma+/pertussis + cohort; during each time period) were included in the DMC estimations, hence actual prescription costs would have been higher, although the impact on the overall DMC would have been small compared to the other costs that were included. Lastly, we did not include non-direct costs (such as workdays lost and over-the-counter medications) or quality of life measures, as these are not available in the data. Had we been able to include these factors, the burden of pertussis (in terms of both cost and morbidity) would likely have been higher.

\section{Conclusion}

The incidence rate of reported pertussis among adults aged $\geq 50$ years with a diagnosis of asthma in England was 9.6 per 100,000 PYFU. Reported pertussis among adults with a diagnosis of asthma resulted in significant excesses of HCRU, which started several months before diagnosis and persisted for months after diagnosis, suggesting lengthy time to diagnosis and to optimal treatment, and prolonged impact of pertussis in this population. Subsequently, DMC were significantly elevated in the asthma + /pertussis + cohort compared to the asthma+/pertussis- cohort. These results highlight the need for increased awareness of the potential for pertussis infection among older adults with a diagnosis of asthma. If such patients with clinical suspicion of pertussis were more routinely tested for this infection, this could result in more - and earlier - diagnosis and treatment, potentially reducing HCRU, DMC, and risk of transmission. Our results also highlight the need to improve preventive measures in this population.

\section{Abbreviations}

A\&E, accident and emergency; $\mathrm{CI}$, confidence interval; COPD, chronic obstructive pulmonary disease; CPRD, Clinical Practice Research Datalink; DMC, direct medical costs; $\mathrm{FEV}_{1}$, forced expiratory volume in 1 second; GINA, Global Initiative for Asthma; GLM, generalized linear model; GP, general practitioner; HCRU, health care resource utilization; HES, Hospital Episode Statistics; HRG, Healthcare Resource Group; IMD, Index of Multiple Deprivation; LRTI, lower respiratory tract infection; NHS, National Health Service; PY, person-years; PYFU, personyears of follow-up; SD, standard deviation; SMD, standardized mean difference; Tdap, tetanus, diphtheria, and acellular pertussis; UK, United Kingdom; US, United States.

\section{Trademarks}

Ventolin and Evohaler are trademarks owned by or licensed to the GSK group of companies.

\section{Data Sharing Statement}

The datasets generated and/or analyzed during the current study are not publicly available as CPRD data are accessed via a license, the terms of which do not allow for the sharing of raw data.

\section{Ethics Approval and Consent to Participate}

The study protocol received CPRD ethics approval via the Independent Scientific Advisory Committee on March 4, 2020 (protocol number 20_043). The study complied with all applicable laws regarding subject privacy. No direct subject contact or primary collection of individual human subject data occurred, and no consent was necessary.

\section{Acknowledgments}

The authors are grateful to Esse Ifebi Herve Akpo and Elisa Turriani (GSK, Belgium) for their support during the early phases of the study. The authors would like to thank Business \& Decision Life Sciences platform for editorial assistance, writing support and manuscript coordination, on behalf of GSK. Gauhar Masgutova and Aurélie Roth (Business \& Decision Life Sciences, on behalf of GSK) coordinated manuscript development and editorial support. Jenny Lloyd (Compass Medical Communications Ltd., on behalf of GSK) provided medical writing support. Part of the results of this paper was presented at the European Respiratory Society (ERS) Conference 2020. The poster's abstract was published in a supplement of the European Respiratory Journal (https://doi.org/10.1183/13993003.con gress-2020.4926, vol 56 Issue suppl 64, 2020). Part of the results have also been presented at ECCMID 2021, but the abstract was not published in an accessible journal. This study is based in part on data from the Clinical Practice Research Datalink obtained under license from the UK Medicines and Healthcare products Regulatory Agency. However, the interpretation and conclusions contained in this report are those of the authors alone. 


\section{Author Contributions}

All named authors meet the International Committee of Medical Journal Editors (ICMJE) criteria for authorship for this article. All authors made a significant contribution to the work reported, whether that is in the conception, study design, execution, acquisition of data, analysis and interpretation, or in all these areas; took part in drafting, revising or critically reviewing the article; gave final approval of the version to be published; have agreed on the journal to which the article has been submitted; and agree to be accountable for all aspects of the work.

\section{Funding}

GlaxoSmithKline Biologicals SA funded this study (study number HO-18-19690) and was involved in all stages of study conduct, including analysis of the data. GlaxoSmithKline Biologicals SA also took in charge all costs associated with the development and publication of this manuscript.

\section{Disclosure}

Amit Bhavsar, Emmanuel Aris, Lauriane Harrington, Kinga Meszaros, Nicolas Jamet, Yan Sergerie and Piyali Mukherjee are employed by the GSK group of companies. Emmanuel Aris, Kinga Meszaros, Yan Sergerie, and Piyali Mukherjee hold shares in the GSK group of companies. Jason C Simeone and Anna Ramond were employed by Evidera Inc. during the time of the study, which received funding from the GSK group of companies to complete the work disclosed in this manuscript. Jason C Simeone's current affiliation is at Real-world Analytics, Cytel Inc, Waltham, MA, USA. Dimitra Lambrelli is employed by Evidera Inc., which received funding from the GSK group of companies to complete the work disclosed in this manuscript. Alberto Papi is a board member of the GSK group of companies, AstraZeneca, Chiesi Farmaceutici, Mundipharma, Novartis, Roche, Sanofi/Regeneron and Zambon. He also declares having received consulting and lecturing fees from the GSK group of companies, AstraZeneca, Avillion, Boehringer Ingelheim, Chiesi Farmaceutici, Mundipharma, Novartis, Sanofi/Regeneron, TEVA and Zambon; consulting fees from Edmond Pharma, Elpen Pharamceuticals, IQVIA, MSD and Roche; lecturing fees from Menarini; grant support from the GSK group of companies, AstraZeneca, Boehringer Ingelheim, Chiesi Farmaceutici, Fondazione Chiesi, Fondazione Maugeri, Menarini, and TEVA; grand support for vaccine studies from the GSK group of companies; and travel expenses reimbursement from the GSK group of companies, AstraZeneca, Boehringer Ingelheim, Chiesi Farmaceutici, Menarini, Mundipharma, Novartis, Roche, Sanofi/Regeneron, TEVA, and Zambon. Louis-Philippe Boulet reports, during the past 36 months, having received support for attending meetings from AstraZeneca and Novartis; research grants having been provided to his institution for participation in multicenter studies from the GSK group of companies, Amgen, AstraZeneca, Merck, Novartis, Sanofi-Regeneron. He also reports that his group of respirologists has received consulting fees from the GSK group of companies, AstraZeneca, Merck, Novartis, SanofiRegeneron; lecturing fees from the GSK group of companies, AstraZeneca, Covis, Merck and Novartis; and royalties. He is also Chair of the Board of Directors of the Global Initiative for Asthma (GINA), First Vice-president of the Global Asthma Organization «InterAsma», member of the Canadian Thoracic Society Respiratory Guidelines Committee, member of the Canadian AllerGen Network of Centres of Excellence, Chair of Knowledge Transfer, Prevention and Education in Respiratory and Cardiovascular Health in Laval University and member of scientific committees for the American College of Chest Physicians, American Thoracic Society, European Respiratory Society, World Allergy Organization, GARD (World Alliance against Chronic Respiratory Diseases, WHO), FIRS and ARIA. These authors declare no other financial or non-financial relationships and activities.

\section{References}

1. Nieves DJ, Heininger U. Bordetella pertussis. Microbiol Spectr. 2016;4(3). doi:10.1128/microbiolspec.EI10-0008-2015

2. Moore A, Harnden A, Grant CC, Patel S, Irwin RS; CHEST Expert Cough Panel. Clinically diagnosing pertussis-associated cough in adults and children: CHEST guideline and expert panel report. Chest. 2019;155(1):147-154. doi:10.1016/j.chest.2018.09.027

3. De Serres G, Shadmani R, Duval B, et al. Morbidity of pertussis in adolescents and adults. $J$ Infect Dis. 2000;182(1):174-179. doi: $10.1086 / 315648$

4. Riffelmann M, Littmann M, Hulsse C, Hellenbrand W, Wirsing von Konig CH. Pertussis: not only a disease of childhood. Dtsch Arztebl Int. 2008;105(37):623-628.

5. Public Health England. Laboratory confirmed cases of pertussis in England. Annual report for 2019 supplementary data tables; 2020. Available from: https://assets.publishing.service.gov.uk/government/ uploads/system/uploads/attachment_data/file/881386/Laboratory_con firmed_cases_of_pertussis_in_England_2019.pdf. Accessed May 28, 2021.

6. Public Health England. Laboratory confirmed cases of pertussis in England: annual report for 2019. Health Prot Rep. 2020;4(8). Available from https://assets.publishing.service.gov.uk/government/ uploads/system/uploads/attachment_data/file/881380/hpr0820_ PRTSSS annual.pdf. Accessed July 14, 2021. 
7. Office for National Statistics. Estimates of the population for the UK, England and Wales, Scotland and Northern Ireland: mid-2019: April 2019 local authority district codes edition of this dataset; 2020. Available from: https://www.ons.gov.uk/peoplepopulationand community/populationandmigration/populationestimates/datasets/ populationestimatesforukenglandandwalesscotlandandnorthernire land. Accessed August 17, 2021.

8. Rønn PF, Dalby T, Simonsen J, Jorgensen CS, Linneberg A, Krogfelt KA. Seroepidemiology of pertussis in a cross-sectional study of an adult general population in Denmark. Epidemiol Infect. 2014;142(4):729-737. doi:10.1017/S0950268813002446

9. Jõgi P, Oona M, Toompere K, Lutsar I. Estimated and reported incidence of pertussis in Estonian adults: a seroepidemiological study. Vaccine. 2015;33(38):4756-4761. doi:10.1016/j.vaccine. 2015.08.007

10. de Melker HE, Versteegh FG, Schellekens JF, Teunis PF, Kretzschmar M. The incidence of Bordetella pertussis infections estimated in the population from a combination of serological surveys. J Infect. 2006;53(2):106-113. doi:10.1016/j.jinf.2005.10.020

11. Aris E, Harrington L, Bhavsar A, et al. Burden of pertussis in COPD: a retrospective database study in England. COPD. 2021;18 (2):157-169. doi:10.1080/15412555.2021.1899155

12. Wilkinson TMA, Van den Steen P, Cheuvart B, et al. Seroprevalence of Bordetella pertussis infection in patients with chronic obstructive pulmonary disease in England: analysis of the AERIS Cohort. COPD. 2021;18(3):341-348. doi:10.1080/15412555.2021.1920904

13. Jenkins VA, Savic M, Kandeil W. Pertussis in high-risk groups: an overview of the past quarter-century. Hum Vaccin Immunother. 2020;16(11):2609-2617. doi:10.1080/21645515.2020.1738168

14. Kandeil W, Atanasov P, Avramioti D, Fu J, Demarteau N, Li X. The burden of pertussis in older adults: what is the role of vaccination? A systematic literature review. Expert Rev Vaccines. 2019;18 (5):439-455. doi:10.1080/14760584.2019.1588727

15. Tan T, Trindade E, Skowronski D. Epidemiology of pertussis. Pediatr Infect Dis J. 2005;24(Suppl 5):S10-S18. doi:10.1097/01. inf.0000160708.43944.99

16. McGuiness CB, Hill J, Fonseca E, Hess G, Hitchcock W, Krishnarajah G. The disease burden of pertussis in adults 50 years old and older in the United States: a retrospective study. BMC Infect Dis. 2013;13:32. doi:10.1186/1471-2334-13-32

17. de Vries R, Kretzschmar M, Schellekens JF, et al. Cost-effectiveness of adolescent pertussis vaccination for the Netherlands: using an individual-based dynamic model. PLoS One. 2010;5(10):e13392. doi:10.1371/journal.pone.0013392

18. Capili CR, Hettinger A, Rigelman-Hedberg N, et al. Increased risk of pertussis in patients with asthma. $J$ Allergy Clin Immunol. 2012;129 (4):957-963. doi:10.1016/j.jaci.2011.11.020

19. Bloom CI, Saglani S, Feary J, Jarvis D, Quint JK. Changing prevalence of current asthma and inhaled corticosteroid treatment in the UK: population-based cohort 2006-2016. Eur Respir J. 2019;53 (4):1802130. doi:10.1183/13993003.02130-2018

20. Liu BC, McIntyre P, Kaldor JM, Quinn HE, Ridda I, Banks E. Pertussis in older adults: prospective study of risk factors and morbidity. Clin Infect Dis. 2012;55(11):1450-1456. doi:10.1093/cid/cis627

21. Buck PO, Meyers JL, Gordon LD, Parikh R, Kurosky SK, Davis KL. Economic burden of diagnosed pertussis among individuals with asthma or chronic obstructive pulmonary disease in the USA: an analysis of administrative claims. Epidemiol Infect. 2017;145 (10):2109-2121. doi:10.1017/S0950268817000887

22. Mbayei SA, Faulkner A, Miner C, et al. Severe pertussis infections in the United States, 2011-2015. Clin Infect Dis. 2019;69(2):218-226. doi:10.1093/cid/ciy889

23. Global Initiative for Asthma. Global strategy for asthma management and prevention; 2020. Available from: https://ginasthma.org/wpcontent/uploads/2020/04/GINA-2020-full-report_-final-_wms.pdf. Accessed August 19, 2021.
24. Esposito S, Stefanelli P, Fry NK, et al. Pertussis prevention: reasons for resurgence, and differences in the current acellular pertussis vaccines. Front Immunol. 2019;10:1344. doi:10.3389/ fimmu.2019.01344

25. Curtis LA, Burns A. Unit costs of health and social care 2019: PSSRU, University of Kent; 2019. Available from: https://kar.kent. ac.uk/79286/. Accessed August 23, 2021.

26. National Health Service (NHS). Amendments to the drug tariff; September, 2019. Available from: https://www.nhsbsa.nhs.uk/sites/ default/files/2019-08/Drug\%20Tariff\%20September\%202019.pdf. Accessed March 26, 2020.

27. National Health Service (NHS). 2018/19 National Cost Collection Data Publication; 2018/2019. Available from: https://www.england. nhs.uk/publication/2018-19-national-cost-collection-data-publication 1. Accessed August 23, 2021.

28. Barker J. Interactive complexity and comorbidity splits in Health Resource Group 4+. Br J Health Care Manag. 2015;21(9):433-439. doi:10.12968/bjhc.2015.21.9.433

29. National Health Service (NHS). HRG4+ 2018/19 reference costs grouper; 2019. Available from: https://digital.nhs.uk/services/ national-casemix-office/downloads-groupers-and-tools/costinghrg4-2018-19-reference-costs-grouper. Accessed March 26, 2020.

30. Weir S, Samnaliev M, Kuo TC, et al. The incidence and healthcare costs of persistent postoperative pain following lumbar spine surgery in the UK: a cohort study using the Clinical Practice Research Datalink (CPRD) and Hospital Episode Statistics (HES). BMJ Open. 2017;7(9):e017585. doi:10.1136/bmjopen2017-017585

31. Ulm K. A simple method to calculate the confidence interval of a standardized mortality ratio (SMR). Am J Epidemiol. 1990;131 (2):373-375. doi:10.1093/oxfordjournals.aje.a115507

32. Gokhale M, Hattori T, Evitt L, et al. Burden of asthma exacerbations and health care utilization in pediatric patients with asthma in the US and England. Immun Inflamm Dis. 2020;8(2):236-245. doi:10.1002/ iid3.299

33. Voorham J, Xu X, Price DB, et al. Healthcare resource utilization and costs associated with incremental systemic corticosteroid exposure in asthma. Allergy. 2019;74(2):273-283. doi:10.1111/all.13556

34. Denlinger LC, Phillips BR, Ramratnam S, et al. Inflammatory and comorbid features of patients with severe asthma and frequent exacerbations. Am J Respir Crit Care Med. 2017;195(3):302-313. doi: $10.1164 / \mathrm{rccm} .201602-04190 \mathrm{C}$

35. Kurz CF. Tweedie distributions for fitting semicontinuous health care utilization cost data. BMC Med Res Methodol. 2017;17(1):171. doi:10.1186/s12874-017-0445-y

36. Aris E, Akpo EI, Bhavsar A, et al. The burden of pertussis in adults with asthma: a retrospective database study in England [abstract]. Eur Respir J. 2020;56:4926.

37. Office for National Statistics. Estimates of the population for the UK, England and Wales, Scotland and Northern Ireland: mid-2012 edition of this dataset Superseded; 2016. Available from: https://www.ons. gov.uk/peoplepopulationandcommunity/populationandmigration/ populationestimates/datasets/populationestimatesforukenglandandwa lesscotlandandnorthernireland. Accessed July 22, 2021.

38. British Medical Journal (BMJ). BMJ best practice. Acute asthma exacerbation in adults; 2021. Available from: https://bestpractice. bmj.com/topics/en-gb/3000085/treatment-algorithm. Accessed July 9, 2021.

39. Stolbrink M, Bonnett LJ, Blakey JD. Antibiotic choice and duration associate with repeat prescriptions in infective asthma exacerbations. J Allergy Clin Immunol Pract. 2019;7(2):548-553.e5. doi:10.1016/j. jaip.2018.07.049

40. National Institute for Health and Care Excellence (NICE). Whooping cough. Available from: https://cks.nice.org.uk/topics/whoopingcough/. Accessed July 8, 2021. 
41. Pluta RM, Lynm C, Glass RM. JAMA patient page. Pertussis. JAMA 2010;304(8):922. doi:10.1001/jama.304.8.922

42. Taylor ZW, Ackerson B, Bronstein DE, et al. Wheezing in children with pertussis associated with delayed pertussis diagnosis. Pediatr Infect Dis J. 2014;33(4):351-354. doi:10.1097/INF.0000000000000176

43. Xie T, Zhong LL, Huang H, et al. [Detection of respiratory pathogens and clinical features in 225 children with acute exacerbation of bronchial asthma]. Zhongguo Dang Dai Er Ke Za Zhi. 2020;22 (11):1198-1203. Chinese.

44. Havers FP, Moro PL, Hariri S, Skoff T; Centers for Disease Control and Prevention (CDC). Epidemiology and prevention of vaccine-preventable diseases: pertussis; 2021. Available from: https://www.cdc.gov/vaccines/ pubs/pinkbook/pert.html. Accessed August 23, 2021.

45. Price D, Castro M, Bourdin A, Fucile S, Altman P. Short-course systemic corticosteroids in asthma: striking the balance between efficacy and safety. Eur Respir Rev. 2020;29(155):190151. doi:10.1183/16000617.0151-2019

46. Meier GC, Watkins J, McEwan P, Pockett RD. Resource use and direct medical costs of acute respiratory illness in the UK based on linked primary and secondary care records from 2001 to 2009. PLoS One. 2020;15(8):e0236472. doi:10.1371/journal.pone.0236472

47. Nationale Lenkungsgruppe Impfen (NaLI). Wichtiger Schutz vor zusätzlichen Infektionen durch Impfschutz gemäß STIKOEmpfehlungen [Important protection against additional infections through vaccination protection according to STIKO recommendations]; 2021. Available from: https://www.nali-impfen.de/impfempfeh lungen/covid-19-und-impfempfehlungen/zusaetzlicher-impfschutzgemaess-stiko-empfehlungen/. Accessed August 19, 2021. German.

48. Robert Koch Institute. Antworten auf häufig gestellte Fragen zum Coronavirus SARS-CoV-2/Krankheit COVID-19 [Answers to frequently asked questions about the SARS-CoV-2 coronavirus/ COVID-19 disease]; 2021. Available from: https://www.rki.de/ SharedDocs/FAQ/NCOV2019/gesamt.html. Accessed June 22, 2021. German.
49. Società Italiana di Pediatria, Società Italiana di Igiene, Federazione Italiana Medici Pediatri. Mantenere ed incrementare le coperture vaccinali nei bambini e negli anziani: evitiamo di aggiungere epidemie alla pandemia [Maintain and increase vaccination coverage in children and the elderly: we avoid adding epidemics to the pandemic]; 2020. Available from: https://www.sip.it/wp-content /uploads/2020/04/CS-CALENDARIO-PER-LA-VITA-24042020.pdf. Accessed June 22, 2021. Italian.

50. World Health Organization. Guidance on COVID-19 for the care of older people and people living in long-term care facilities, other nonacute care facilities and home care; 2020. Available from: https://iris.wpro.who.int/bitstream/handle/10665.1/14500/COVID-19emergency-guidance-ageing-eng.pdf. Accessed June 22, 2021.

51. Global Initiative for Chronic Obstructive Lung Disease. Global strategy for the diagnosis, management, and prevention of chronic obstructive pulmonary disease; 2021. Available from: https://gold copd.org/2021-gold-reports/. Accessed November 20, 2020.

52. Centers for Disease Control and Prevention (CDC). Adult immunization schedule; 2021. Available from: https://www.cdc.gov/vaccines/ schedules/hcp/imz/adult.html. Accessed August 26, 2021.

53. National Health Service (NHS). Whooping cough vaccination in pregnancy; 2019. Available from: https:/www.nhs.uk/pregnancy/ keeping-well/whooping-cough-vaccination/. Accessed July 9, 2021.

54. GOV.UK. Immunisation against infectious disease; 2020. Available from: https://www.gov.uk/government/collections/immunisationagainst-infectious-disease-the-green-book. Accessed July 23, 2021.
Journal of Asthma and Allergy

\section{Publish your work in this journal}

The Journal of Asthma and Allergy is an international, peer-reviewed open-access journal publishing original research, reports, editorials and commentaries on the following topics: Asthma; Pulmonary physiology; Asthma related clinical health; Clinical immunology and the immunological basis of disease; Pharmacological interventions and

Submit your manuscript here: https://www.dovepress.com/journal-of-asthma-and-allergy-journal

\section{Dovepress}

new therapies. The manuscript management system is completely online and includes a very quick and fair peer-review system, which is all easy to use. Visit http://www.dovepress.com/testimonials.php to read real quotes from published authors. 